\title{
Measured daylighting potential of a static optical louver system under real sun and sky conditions
}

\author{
Corresponding author email address: kkonis@usc.edu
}

\begin{abstract}
By utilizing highly specular surfaces and engineered profile geometry, optical sunlight redirecting systems integrated into the overhead "clerestory" zone of the building facade present the potential to enlarge the daylighting zone by redirecting the luminous flux incident on the window deeper into the space than conventional shading systems. In addition, by developing system geometry to redirect daylight to specific zones within the space, optical light redirecting systems have the potential to avoid the glare conditions commonly produced by conventional facade shading systems that direct significant amounts of daylight below head height into the occupant's field of view. In this case study, side-by-side comparisons were made over solstice-to-solstice changes in sun and sky conditions between an optical louver system (OLS) and a conventional Venetian blind set at a horizontal slat angle and located inboard of a south-facing, small-area, clerestory window in a full-scale office testbed. Daylight autonomy (DA), window luminance, and ceiling luminance uniformity were used to assess performance. The performance of both systems was found to have significant seasonal variation, where performance under clear sky conditions improved as maximum solar altitude angles transitioned from solstice to equinox. Although the OLS produced fewer hours per day of DA on average than the Venetian blind, the OLS never exceeded the designated 2000 $\mathrm{cd} / \mathrm{m}^{2}$ threshold for window glare. In contrast, the Venetian blind was found to exceed the visual discomfort threshold over a large fraction of the day during equinox conditions (from 40 to $64 \%$ of the test day between August 22 and October 12). Notably, these peak periods of visual discomfort occurred during the best periods of daylighting performance. Luminance uniformity was analyzed using calibrated high dynamic range luminance images. Under clear sky conditions, the OLS was found to increase the luminance of the ceiling as well as produce a more uniform distribution of luminance over the ceiling. Compared to conventional venetian blinds, the static optical sunlight redirecting system studied has the potential to significantly reduce the annual electrical lighting energy demand of a daylit space and improve the quality from the perspective of building occupants by consistently transmitting useful daylight while eliminating window glare.
\end{abstract}

Keywords: daylighting, sunlight redirecting system, optical louver system, field measurements, high dynamic range luminance images

\section{Introduction}

Electrical lighting energy consumption in U.S. commercial buildings accounts for 3.69 quad annually [1]. Of this, a recent estimate by Shehabi et al. found that 2.21 quad $(60 \%)$ is consumed by electrical lighting in perimeter zones located 0-12.2m from the facade during typical daytime work hours (8:00-18:00) [2]. Consequently, the delivery of sufficient daylight from windows has the potential to reduce annual electrical lighting energy demand by minimizing the need for electrical lighting in the perimeter zone during daylight hours. However, as a general rule of thumb, conventional windows cannot provide useful daylight beyond approximately 1.0-1.5 times the head height of the window [3], leading to useful daylight for areas within a distance of $0-4.5 \mathrm{~m}$ from the facade. Subdivision of the window wall into a lower "view" zone and an upper "clerestory" zone for daylight transmission is a common strategy to extend the daylight zone beyond this distance. Because occupants often reduce the daylight transmission of the view zone with shading devices to maintain visual comfort, the clerestory zone is designed to serve as the primary means of daylight delivery into the space. For single-occupancy offices, this strategy can be effective. Due to the relatively 
shallow office depth, typically $3.05 \mathrm{~m}$ to $6.1 \mathrm{~m}$, the occupant is located relatively close to the window wall and the clerestory is not within the occupant's primary field of view. Because many occupants working in open plan offices are located at a greater distance from the facade, the relatively lower ambient light levels combined with a more direct view of the bright clerestory can cause uncomfortable luminance contrasts, leading to the deployment of shading devices to maintain visual comfort. As an example, in a number of case study evaluations conducted in the UK, Bordass et al. [4] noted that tall windows intended to enable greater daylight penetration to open plan workspaces were often found with the shades closed and the electric lights turned on. Bordass reported that the cause of the default state of "shades down, lights on" was the need to resolve the visual discomfort experienced by those who worked the farthest distance from the facade and did not have control over the shades. In addition to the unnecessary use of electrical lighting that can result from the shading of clerestory windows, electric lights may be switched on by occupants in daylit spaces even when sufficient daylight is provided by windows because the contrast in luminance between interior surfaces adjacent to the facade and surfaces away from the facade causes the space to appear dark or "cave-like" to occupants.

Many systems have been developed for the clerestory zone with the goal of increasing the daylit area of the floor plate. A comprehensive description of existing systems can be found in [5] (see chapter 4). These include light shelves, anidolic daylighting systems, translucent panels, prismatic structures, and Optical Louver Systems (OLS). By reflecting daylight to the ceiling, light shelves have been shown to deliver useful daylight at slightly greater depths from the facade than conventional windows [6]. However, at low sun angles, conventional light shelves fail to block direct sun, which can lead to glare from direct view of the solar disc and, in turn, deployment of interior shading devices. Further, external light shelves of sufficient depth as to be effective in daylight redirection and perimeter shading are rarely implemented in commercial building facades due to additional structuring required for wind loads and to support the system itself. More advanced light shelve designs, such as those developed by Beltran et al. [7], as well anidolic daylighting systems [8], use an arrangement of optical components to redirect daylight and effectively control glare. However, these more advanced designs have failed to be broadly adopted by architects due in part to their large size, complexity, and challenges with integration into otherwise two-dimensional (flat) facade systems popular among architects. Translucent panels with near-lamberitan diffusing properties, such as those characterized by Reinhart and Andersen [9], redirect incident daylight towards the ceiling but also downward into the view zone of occupants. Although these panels can be easily incorporated into a façade system, the downward-redirected light, as well as the relatively high luminance of the panel itself, can become a source of glare. Prismatic structures have been in use for over a century for lighting applications [10] and work (in sidelighting applications) by refracting light to the ceiling plane for a range of incident angles. Recent developments in the application of prismatic structures for sidelighting have led to the development of prismatic window films which can be adhered to both new and existing glazing systems, creating the possibility of broad application at low cost. However empirical assessment has shown than the current film technology produces perceptible levels of glare under clear sky conditions [11]. Optical louver systems utilize reflective mirrored coatings to reflect daylight to the ceiling while blocking direct view of the window and can be incorporated into the clerestory zone as static louvers (e.g. [12], [13]) or as adjustable lamellas (see systems evaluated in [14]). Static optical louver systems offer the benefit of not requiring daily or seasonal adjustments in tilt angle, which makes them a potentially more practical and reliable technology for broad application in clerestory zones. However, as a consequence, the profile geometry of static systems must be designed to function effectively over the full seasonal range in incident sun angles.

With the increasing trend of open plan workspaces designed to comply with the daylight illuminance criteria specified in green building rating systems (e.g., Leadership in Energy and Environmental Design (LEED) [15], Building Research Establishment Environmental Assessment Method (BREEAM) [16]), it is important for daylighting strategies to consider human factors issues of visual comfort and luminance uniformity in addition to providing sufficient illumination for performance of visual tasks. When located in the clerestory zone, OLS have the potential to meet daylight illuminance requirements while providing improved visual comfort and light distribution relative to conventional shading systems. Recent developments in computer-based lighting simulation tools, namely the simulation of complex fenestration systems using bidirectional scattering distribution functions [17] and the development of the three-phase simulation method [18] have made it possible to accurately solve for high flux light transport through 
optically complex daylight redirecting devices such as OLS to produce annual assessments of daylighting performance. These new capabilities are making it easier to assess the application of optically complex fenestration in the design of low-energy buildings. However, the Architecture, Engineering and Construction (AEC) industry is extremely risk averse, and slow to adopt promising technologies without proof of performance in realistic field conditions.

The goal of this study was to compare the daylighting potential of a recently developed OLS installed in the clerestory zone of a facade against a conventional Venetian blind over seasonal changes in sun and sky conditions to test if the optical surface treatment and specific geometry of the OLS consistently resulted in useful daylight illuminance levels and reduced visual discomfort.

\section{Measurements and Procedures}

\subsection{Experimental set-up}

Experimental tests were conducted in the Window Testbed Facility located in Berkeley, California (latitude $37^{\circ} 4^{\prime} \mathrm{N}$, longitude $122^{\circ} 1^{\prime} \mathrm{W}$ ) from February 2 to January 19,2011 . The facility consists of three, identical, south-facing, side-by-side, furnished test rooms built to represent a commercial single-occupancy office. The test rooms were unoccupied during this study. Interior surface reflectances of the floor, walls, and ceiling, are $0.18,0.85$, and 0.86 , respectively, as measured by a Minolta CM-2002 spectrophotometer.

For these tests, all areas of the window wall, with the exception of the clerestory opening (Fig. 1), were completely occluded with black-out cloth. The clerestory opening was $2.65 \mathrm{~m}$ wide by $0.762 \mathrm{~m}$ tall and glazed with two, dual-pane, low-emittance windows (type = Viracon VRE-67 glass; visible transmittance $=0.62$, back surface visible reflectance ${ }^{1}=0.256$ ) separated by a $63.5 \mathrm{~mm}$ wide vertical mullion. The window-area-to-wall ratio (WWR) of the vision portion of the window was 0.174 , assuming a floor-tofloor height of $3.81 \mathrm{~m}$. All testing was conducted with the electrical lighting turned off.

\section{$<$ FIGURE $>$}

Fig. 1. Cross-sectional view of the test office showing the unblocked clerestory region, location of photosensors and digital cameras. Also shown is the subdivision of the ceiling into six equal zones for the luminance analysis. Note: Dimensional units are in meters.

The OLS is a commercial product (LightLouver ${ }^{\mathrm{TM}}$ Daylighting System [13]), consisting of $65 \mathrm{~mm}$ deep, vertically-stacked, concave-up, polished mirrored louvers (approximately $85 \%$ total visible light reflectance) (Fig. 2). The louver geometry was designed to redirect incident sunlight uniformly onto the ceiling and to block sunlight redirected below head height that would cause glare. The system completely obstructs views to the outdoors. The system is static, requiring no adjustment over the year, and was placed within the framed opening of the window, almost flush against the face of the glass.

\section{$<$ FIGURE $>$}

Fig. 2. Left: Side view of the OLS prior to being installed on the inward face of the clerestory glazing. The unit is then slid on the horizontal brackets at the top of the OLS and into the frame cavity. Middle: Interior view of the installed OLS. Right: Interior view of the installed Venetian blind reference condition.

The OLS was compared to a static, horizontal Venetian blind reference condition. The Venetian blind consisted of single, $25 \mathrm{~mm}$ wide slats with a matte white coating in a fully lowered position covering the entire clerestory aperture (Fig. 2). The blind was installed inboard of the window frame, $133 \mathrm{~mm}$ from the face of the glass. Slat angles were maintained at a horizontal position throughout the testing to represent

\footnotetext{
${ }^{1}$ NOTE: back surface visible reflectance is the visible reflectance of the back surface (room side facing) of the IGU at normal incidence. It's a useful number since it indicates how much of the light reflected off the lightlouver system gets reflected back to the interior (25\%). Most (75\%) of the visible light reflected off LL back toward the window goes back out the window.
} 
"best case" conditions for a typical clerestory window where slat positioning intended to maintain effective daylight transmission.

\subsection{Measured data}

Two types of measures were used in this study. The first was illuminance recorded horizontally at the workplane at distances of $0.762 \mathrm{~m}, 2.286 \mathrm{~m}$, and $3.81 \mathrm{~m}$ from the facade and $0.762 \mathrm{~m}$ above the floor using photometric sensors (type $=$ Licor LI-210, nominal accuracy $=3 \%$, range $=0-15,0001 \mathrm{~lx}$ ) at 1-min intervals. Differences in average workplane illuminance were within $2.6 \%$ between rooms over a 4-hour interval and within $1.4 \%$ over a 12 -hour interval (Fig. 3).

\section{$<$ FIGURE $>$}

Fig. 3. Comparison in average workplane illuminance between test rooms for one day under clear sky conditions with all windows in the test rooms unshaded. Each bar indicates the average of both photosensors located $3.81 \mathrm{~m}$ from the facade for each 4-hour subinterval. Annotation (in \%) on each bar indicates the percentage increase or decrease in average illuminance of room $C(O L S)$ over room A (Venetian blind) for each respective interval. NOTE: Room B was not used in the present study.

Second, calibrated luminance maps were acquired every 5 minutes from two digital CCD cameras located in each test room as shown in Fig. 1. High dynamic range (HDR) luminance maps store luminance data on a "per-pixel" scale, enabling the variation in scene luminance from a specific viewpoint to be quantified and analyzed. Each HDR image was composited from a set of nine, 1536 x 1536 pixel, LDR images, exposure-bracketed in $1 \mathrm{EV}$ steps. Compositing was performed by the program hdrgen [19], which converts the RGB pixel values of exposure bracketed LDR images into real-world luminances following the radiometric self-calibration process develop by Mitsunaga and Nayar [20].

High dynamic range photography was not developed specifically for photometry and several factors must be considered in assessing the precision and repeatability of measurements. To correct for the light fall off typical of wide-angle camera systems, a "digital filter" was applied to each HDR image as a post-process in Radiance using the method developed by Inanici and Galvin [21]. To control for unstable lighting conditions and as an additional calibration step, the global vertical illuminance computed from the image was compared to the average of two readings from an adjacent vertical illuminance sensor (type=Licor LI210 , cosine-corrected, nominal accuracy $=3 \%$ ): immediately before and after acquisition of the bracketed set of images. The image was then uniformly scaled by adjusting the exposure line of the image file header so that the global vertical illuminance computed from the image matched the average of the two illuminance readings. A calibration test determined that measurement errors were within $\pm 6 \%$ on average of reference measurements within a range of $0-11,000 \mathrm{~cd} / \mathrm{m}^{2}$ [14]. Finally, because the calibration function is derived for a specific illuminant (e.g. D65), the accuracy of luminance calculations is affected as the spectral properties of the light source change. This is an important concern for dynamic daylighting conditions, as changes in sky conditions (clear vs. overcast) and time of day (sunrise vs. noon) lead to different Spectral Power Distributions (SPD)s. However, prior testing examining the accuracy of measurements under various illuminants found that the error margin was $10 \%$ or less [21]. Because the present study design is structured as paired comparisons with concurrent measurements, any error introduced by changes in the SPD will affect both cases equally and is not expected to impact comparisons between cases. A complete description of the HDR acquisition system is given in [14].

Data were acquired from 6:00 to 18:00 Standard Time (ST) from February 2, 2010 to January 19, 2011. The data collection period of 6:00 to 18:00 was chosen to align with the 12-hours of daylight present on equinox conditions. While this interval excludes some daylight hours during summer months and includes some non-daylight hours during winter months, it leads to a symmetrically-balanced assessment of daily performance, as well as annual performance (when data are grouped categorically by time of year). This interval was preferred over making assumptions for a "typical" workday which is growing more difficult to predict as work schedules in U.S. commercial buildings shift away from the traditional 9:00 to 17:00 
workday due to many employers allowing for more flexibility in working hours. During this period, the OLS and Venetian blind were tested on a rotational schedule to accommodate other test conditions unrelated to this study. As a result of technical issues with the installation, no data were collected between March 1 and April 30, 2010.

Sky conditions were expected to have a significant influence on performance outcomes. Therefore, a sky classification for each test day was determined using the method developed by [22]. The classification is based on two parameters: 1) the fraction of time, $s$, that the direct normal irradiation ${ }^{2}$ exceeds $120 \mathrm{~W} / \mathrm{m}^{2}$, and 2) $\boldsymbol{U}$, the natural logarithm of the average of the absolute values of the change in global horizontal illuminance (lx) over a one-minute span. If $s$ is less than 0.03 , then conditions are considered to be overcast. If $s$ is greater than or equal to 0.75 , conditions are characterized as clear. For solar fractions between this range, if $\boldsymbol{U}<(10-6 \mathrm{~s})$, conditions are considered cloudy. Otherwise, conditions are considered dynamic. The resulting number of test days and sky conditions are summarized in Fig. 4.

\section{$<$ FIGURE $>$}

Fig. 4. Classification and distribution of sky conditions during the test period. Values of " $N$ " in parentheses indicate the number of days where both the test and reference condition had usable luminance (HDR) data (plotted as solid circles), followed by the number of days where both the test and reference condition had workplane illuminance data (plotted as outlined circles).

\subsection{Performance metrics}

Daylight autonomy (DA) is a general measure of daylight sufficiency and has been computed in various ways by the daylighting community over the past decade, a review of which is given in [23]. DA is essentially an indicator for when a horizontal visual task illuminance threshold can be maintained by daylight alone. In this study, DA was computed as the percentage of day (6:00-18:00, inclusive of nighttime periods) when a specified workplane illuminance threshold was satisfied by daylight at the two rear workplane illuminance sensors, $3.81 \mathrm{~m}$ from the facade (Fig. 1). Workplane sensors are offset by $0.76 \mathrm{~m}$ perpendicular from the east and west sidewall respectively. Since the rear of the room typically receives the least amount of daylight, this approach is intended to be an indication of the percentage of day when $100 \%$ of the floor area met the DA threshold criteria. Two thresholds were used to report DA. The first is a threshold of $300 \mathrm{~lx}$, which was chosen to represent a consensus-based horizontal illuminance requirement for North American office spaces [24]. The second is a threshold of 100 lx, which was chosen to reward lower absolute levels of daylight that still may be perceived as useful. This second threshold conforms to the lower bound of the Useful Daylight Illuminance (UDI) paradigm, developed by Nabil and Mardaljevic [25] for climate-based daylight modeling and evaluation. The lower threshold is based on field studies documenting occupant acceptance of daylight levels that fall below $3001 \mathrm{x}$ [26, 27] as well as the author's own field research conducted in a daylit office building [28]. The latter study used logistic regression models developed from repeated measures subjective feedback paired with physical lighting measures to predict satisfaction with daylight levels. Probabilistic models showed a high level of probability that occupant satisfaction with daylight when daylight illumiances were between 100-300 1x. For one daylight perimeter zone, a 0.7 probability was found at daylight levels of 100 1x (see p. 321 of [28]). While daylight levels between 100 and $300 \mathrm{~lx}$ may not be considered acceptable by all occupants in a zone, it is important to not discount performance in the $100-300$ lx range entirely. As daylight illuminance levels below $300 \mathrm{~lx}$ have been shown to be acceptable to some occupants, the additional $100 \mathrm{~lx}$ threshold is maintained as an additional indicator of performance.

Due to the blocking of light from the lower windows, the visual comfort assessment of both systems could not be performed using established discomfort glare metrics such as the Unified Glare Rating (UGR) [29] or Daylight Glare Probability (DGP) [30]. Glare metrics compute outcomes using a hemispherical luminance distribution. In the present study, the blocking of lower windows combined with the electrical lighting remaining off during the duration of the study leads to an unrealistic luminance contrast between the clerestory windows and the interior surfaces. Consequently, the visual comfort assessment is limited to

\footnotetext{
${ }^{2}$ Direct normal irradiance was measured using a pyroheliometer.
} 
an assessment of the absolute luminance of the clerestory zone, which is evaluated against a hypothetical visual task using luminance contrast ratio limits. To compare performance in regard to visual discomfort, the average luminance across each clerestory window pane was computed from the luminance images taken at the back of the test room. This view point location was chosen to represent a view from a corezone workstation, where the clerestory window would be more likely to appear in the occupant's task view relative to a workstation in the perimeter zone. Because the average luminance between panes was not found to vary significantly at any given time, a single average of the two panes was used. Luminance levels were compared to threshold value derived from the Illuminating Engineering Society of North America (IESNA) guidelines for acceptable levels of non-uniformity [24]. This is expressed in terms of luminance ratios between surfaces in the field of view. The basis for the guideline is the physiological phenomenon called transient adaptation, a phenomenon associated with reduced visibility after viewing a higher or lower luminance than that of the task. To avoid visual performance decrements, a maximum allowable contrast of [1:10] is permitted between the task, surroundings, and background. In this study, the visual task was defined as a hypothetical visual display terminal (VDT) with a constant luminance of $200 \mathrm{~cd} / \mathrm{m}^{2}$. The clerestory region was assumed to be a source of visual discomfort if it exceeded the luminance of the task by a factor of 10 (i.e., 1:10 ratio for "background region"), leading to the maximum allowable luminance of $2000 \mathrm{~cd} / \mathrm{m}^{2}$.

The delivery of daylight from overhead has the benefit of lighting the zone without the glare that is commonly associated with sidelighting. The ceiling was considered as a source of "glare-free" light provided that the absolute luminance of any given region of the ceiling did not exceed the visual discomfort threshold $\left(2000 \mathrm{~cd} / \mathrm{m}^{2}\right)$. To quantify the differences in luminance distribution between systems in terms of both magnitude and uniformity, a method was developed to compute the average luminance for each of a number of unique, evenly-spaced zones (Fig. 5) defined by the room geometry.

Average region luminance was computed by masking off the irrelevant pixels in the luminance image then computing the average pixel luminance value for the unmasked portion of the image. This was

accomplished by post-processing the luminance images using a custom C-shell script invoking a number of Radiance programs [31]. As illustrated in Fig. 5, the ceiling was subdivided parallel to the facade into six, $0.762 \times 3.05 \mathrm{~m}$ zones. Each region was then symmetrically divided perpendicular to the facade to produce a total of 12 zones in total. Because the overhead indirect lighting fixtures occluded a portion of the ceiling, the boundaries of affected zones were drawn to omit the fixtures. In addition, portions of ceiling zones that included objects such as cords (R3) or the ceiling supply air diffuser (L1, R2) were not included in the definition of the region. As a result of both the position of the camera lens $(0.23 \mathrm{~m})$ from the interior face of the mullion) as well as the need to mask out the ceiling diffuser, zones L1 and R1 are approximately half the depth of the other zones. A buffer of 3 pixels was used to separate each region to avoid measurement errors from slight movements in camera position that might occur over the course of testing.

\section{$<$ FIGURE $>$}

Fig. 5. Image of test room with superimposed subdivision grid used to define individual ceiling zones for analysis. View is from the camera positioned at the facade looking towards the back wall of the test room.

\section{Results and Discussion}

\subsection{Workplane illuminance and daylight autonomy}

Fig. 6 compares seasonal performance between the OLS and the reference Venetian blind under clear sky conditions using the metric of daylight autonomy (DA). Data represent paired comparisons between systems under identical sky conditions. The performance of both systems was found to be related to the maximum daily altitude angle of the sun where, based on the DA criterion of $300 \mathrm{~lx}\left(\mathrm{DA}_{300}\right)$, the greatest DA outcomes were achieved during the fall equinox and decreased significantly approaching the summer and winter solstices. Notably, the performance of the OLS was comparable to the Venetian blind approaching the winter solstice, and relative performance decreased approaching the summer solstice. 
Based on the 100 lx criterion, the performance of the Venetian blind was found to increase from winter to summer solstice, where the OLS followed a similar trend as the $300 \mathrm{~lx}$ criterion. The increase for both systems is partly due to the increased daylight hours approaching the summer solstice. On average, the reference Venetian blind produced 2.7 more hours of $\mathrm{DA}_{300}$ per day for maximum daily altitude angles between 62 and 76 degrees, and 1 more hour for angles between 44 and 55 degrees under clear skies. For angles between 28 and 38 degrees, the OLS was found to perform slightly better overall (10 minutes more $\mathrm{DA}_{300}$ per day on average). For reference, this latitude had maximum solar altitude range of 29.5-76.5. Performance under cloudy, dynamic and overcast sky conditions are presented in Fig. 7, Fig. 8 and Fig. 9 respectively. Due to the fewer test days available for these sky conditions as well as the dynamic nature of non-clear skies, these results should be considered as illustrative of the variation in performance that should be expected under non-clear skies rather than indicative of annual performance. Under non-clear sky conditions, the Venetian blind produced longer periods of daylight autonomy based on both the $300 \mathrm{~lx}$ and $100 \mathrm{~lx}$ thresholds compared with the OLS. As anticipated, the performance of both systems was lower on non-clear test days compared with clear skies, and performance under non-clear skies was less affected by seasonal changes in sun position. Both systems recorded the worst under overcast sky conditions (Fig. 9), illustrating the limitations of static, opaque light redirecting systems which obstruct admission of diffuse light.

\section{$<$ FIGURE $>$}

Fig. 6. Seasonal performance comparison based on daylight autonomy (DA) between the OLS (blue) and the reference Venetian blind (red) under clear sky conditions (6:00-18:00 ST). Two different criteria are set for DA. The solid circles/curves represent performance based on a DA criterion of $300 \mathrm{~lx}$, the outlined circles/dashed curves represent performance based on a DA criterion of $100 \mathrm{~lx}$. [Workplane illuminance was measured at the back of the room].

\section{$<$ FIGURE $>$}

Fig. 7. Seasonal performance comparison based on daylight autonomy (DA) between the OLS (blue) and the reference Venetian blind (red) under cloudy sky conditions (6:00-18:00 ST).

\section{$<$ FIGURE $>$}

Fig. 8. Seasonal performance comparison based on daylight autonomy (DA) between the OLS (blue) and the reference Venetian blind (red) under dynamic sky conditions (6:00-18:00 ST).

\section{$<$ FIGURE $>$}

Fig. 9. Seasonal performance comparison based on daylight autonomy (DA) between the OLS (blue) and the reference Venetian blind (red) under overcast sky conditions (6:00-18:00 ST). 


\subsection{Discomfort glare from the clerestory window}

Fig. 10 illustrates the seasonal variation in performance between the OLS and Venetian blind under clear sky conditions based on the metrics of median (solid circle) and maximum (open circle) window luminance. Due to data acquisition issues, only 21 of 23 total test days are available for this analysis. Data represent paired comparisons between systems under identical sky conditions. Because data was sampled at regular intervals between 6:00-18:00, conditions were equal to or "worse" than the median value for 6 hours each day. Table 1 presents a daily summary of seasonal variation in window luminance for the OLS and Venetian blind under clear sky conditions shown in Fig. 10. The label "\% Time Abv. $\left(2000 \mathrm{~cd} / \mathrm{m}^{2}\right)$ "" indicates the percent of the 12-hour test period (6:00 - 18:00) when the average luminance of the clerestory exceeded the visual discomfort threshold of $2000 \mathrm{~cd} / \mathrm{m}^{2}$. The Venetian blind was found to exceed the visual discomfort threshold over a large fraction of the day during fall equinox conditions (from 40 to $64 \%$ of the test day between August 22 and October 12). Notably, this was the same seasonal period when the Venetian blind was found to have the best daylighting performance based on the $\mathrm{DA}_{300}$ criterion (Fig. 6). In contrast, the OLS never exceeded the discomfort threshold.

Fig. 10. Seasonal comparison of average clerestory window luminance between the OLS (blue) test system and the reference Venetian blind (red) under clear sky conditions based on median (solid circle) and maximum (outlined circle) luminance. Luminance was measured at a distance of $3.8 \mathrm{~m}$ from the window at seated eye height. The horizontal green line indicates the designated threshold for visual discomfort $\left(2000 \mathrm{~cd} / \mathrm{m}^{2}\right)$.

Table 1. Seasonal variation in window luminance for OLS (test condition) and Venetian blind (reference condition) under clear sky conditions. "\% Time Abv. $\left(2000 \mathrm{~cd} / \mathrm{m}^{2}\right)$ " indicates the percent of the 12 -hour test period $(6: 00-18: 00)$ when the average luminance of the clerestory exceeded the visual discomfort threshold $2000 \mathrm{~cd} / \mathrm{m}^{2}$. 


\subsection{Magnitude and distribution of luminous flux across the ceiling plane}

Fig. 11 provides a visual comparison of the difference in daylight distribution in the room between the OLS and reference Venetian blind. Selected at a time of day when the solar azimuth was perpendicular to the south-facing facade, the OLS is shown to distribute daylight more uniformly across the ceiling and walls perpendicular to the facade, as well as produce greater luminance levels at the back of the room. In contrast, the reference Venetian blind distributes roughly an equal amount of light to the walls as to the ceiling, and the transmitted light is concentrated on the surfaces immediately surrounding the window aperture. The upper back wall luminance is significantly greater than the reference case (Fig. 11 bright yellow), indicating that had this been an open plan office, for which the OLS was designed, the luminous flux would have been distributed much deeper than the physical limits of the test room ( $4.57 \mathrm{~m}$ depth).

\section{$<$ FIGURE $>$}

Fig. 11. High dynamic range luminance map of test OLS condition (left) and reference Venetian blind condition (right), acquired near-simultaneously on February 7, 2010 at 12:22 ST (clear sky conditions) from the camera looking towards the back of the room with falsecolor tone mapping (yellow indicates luminance $\geq 2000 \mathrm{~cd} / \mathrm{m}^{2}$ (Nits)).

Fig. 12, 13 show the daily luminance profiles for each of the ceiling zones over the 12-h hour test interval on a clear (February, 7) and overcast day (February, 21) respectively. The left and right sides of the six ceiling zones are shown on the same plot with the OLS profile shown in blue and the reference Venetian blind profile shown in red. The dotted horizontal blue and red lines indicate the average luminance of the OLS and Venetian blind respectively over the four-hour sub-intervals (6:00-10:00, 10:00-14:00, 14:0018:00).

As illustrated by Fig. 11, the horizontal Venetian blind produced significantly greater ceiling luminances at zones adjacent to the facade (zones 1 and 2) than for the remaining zones (zones 3-6) under clear skies. In contrast, the OLS produced greater ceiling luminances towards the rear of the room. Referring to Fig. 12, the increased ceiling luminance of the OLS zone 6 is partially the result of additional light being reflected from the adjacent back wall (Fig. 11). Relative to the Venetian blind, Fig. 12 shows that the OLS produced greater ceiling luminances for zones 3 through $6(55 \%, 69 \%, 100 \%$ and $153 \%$ increase in zone luminance, respectively) on average during the 10:00-14:00 sub-interval. However, the OLS was comparable or "worse" than the Venetian blind over the other two sub-intervals.

Fig. 14 shows the resultant workplane illuminance levels over the same days shown in Fig. 12, 13. Daylight reflected off of the ceiling and walls contribute to workplane illuminance. It is assumed that the lower view window will contribute daylight to the areas closest to the window. The upper clerestory window needs to supplement daylight levels in the rear of the office in order to justify its use. With a wall and ceiling surface reflectance of $85 \%$ and $86 \%$ respectively, the OLS was found to increase rear-zone workplane illuminance levels by $10 \%$ during the 10:00-14:00 period and reduce levels by approximately $35 \%$ during the other two periods (6:00-10:00 and 14:00-18:00) of the clear sunny day. Under overcast diffuse sky conditions, the OLS reduced rear-zone illuminance levels by approximately $50 \%$ compared to the reference case for each 4-hour period (Fig. 14). 


\section{$<$ FIGURE $>$}

Fig. 12. Comparison of ceiling luminance by zone between the OLS (blue) and the reference Venetian blind (red) under clear sky conditions on February 7, 2010. Numbers in parentheses indicate the percentage increase or decrease in average zone luminance (over each 4-h sub-interval) by the OLS over the reference Venetian blind. Numbers in square brackets indicate the average magnitude difference in $\mathrm{cd} / \mathrm{m}^{2}$. Zone 1 is closest to the window and Zone 6 is the farthest from the window.

\section{$<$ FIGURE $>$}

Fig. 13. Comparison of ceiling luminance by zone between the OLS (blue) and the reference Venetian blind (red) under overcast sky conditions on February 21, 2010. Numbers in parentheses indicate the percentage increase or decrease in average zone luminance (over each 4-h sub-interval) by the OLS over the reference Venetian blind. Numbers in square brackets indicate the average magnitude difference in $\mathrm{cd} / \mathrm{m}^{2}$.

\section{$<$ FIGURE $>$}

Fig. 14. Left: Comparison of workplane illuminance levels between the OLS (blue) and the reference Venetian blind (red) under clear sky conditions on February 7, 2010. Right: Comparison of workplane illuminance levels between the OLS (blue) and the reference Venetian blind (red) under overcast sky conditions on February 21, 2010. Workplane illuminance levels represent the average between the two workplane sensors at the rear of the test room. 
Fig. 15 compares the OLS to the Venetian blind based on metrics of average ceiling luminance and uniformity between zones on average from 10:00-14:00 under clear sky conditions. These data summarize paired comparisons over $(\mathrm{N}=23)$ days with clear sky conditions. The solid horizontal green line indicates the average luminance of ceiling zones 2 through 6 . The dotted green lines indicate the maximum and minimum average zone luminances and the numbers in parentheses indicate the degree of uniformity between zones expressed in terms of a simple ratio of maximum:minimum. Fig. 15 shows that, during the middle of the day, the OLS redirected nearly twice the amount of daylight to the ceiling on average compared with the Venetian blind reference condition and with a more uniform light distribution. Fig. 16 presents the same comparison using combined data from the other two sub-intervals (6:00 - 10:00 and 14:00 - 18:00), where performance was comparable to the Venetian blind for both absolute ceiling luminances and luminance uniformity. Due to the installation of the OLS at a distance of $0.53 \mathrm{~m}$ vertically from the ceiling, redirected sunlight never reached zone 1 directly (Fig. 1, 2). Therefore, the luminances recorded for zone 1 are not representative of the performance of the OLS in typical applications where it would be installed directly adjacent to the ceiling plane. Consequently, zone 1 was omitted from the final analysis. The relatively lower luminance levels recorded for zone 1 are included in the sample daily ceiling zone luminance profiles shown in Fig. 12, 13).

\section{$<$ FIGURE $>$}

Fig. 15. Summary performance comparison between the OLS (blue) and the reference Venetian blind (red) under clear sky conditions based on average ceiling region luminance and region uniformity over the sub-interval 10:00-14:00 ST.

\section{$<$ FIGURE $>$}

Fig. 16. Annual performance comparison between the OLS (blue) and the reference Venetian blind (red) under clear sky conditions based on average ceiling region luminance and region uniformity over the sub-intervals 6:00-10:00 and 14:00-18:00.

Based on the average of zones 2-6 over the monitored period, Fig. 17 summarizes the percentage increase or decrease in ceiling luminance produced by the OLS compared to the Venetian blind. Data are given for each sky condition and for each of the three sub-intervals of the day. Due to relatively fewer number of total days for cloudy and dynamic sky conditions, results are likely to be illustrative rather than indicative of annual performance. The overcast sky condition is purportedly independent of solar position and is therefore indicative of annual performance. The results show that clear sky conditions produced the greatest increase in ceiling luminance during the middle of the day, with the remaining sky conditions following the same trend.

\section{$<$ FIGURE $>$}

Fig. 17. Percentage increase or decrease in overall ceiling luminance (average of zones 2-6) by the OLS relative to the Venetian blind reference per sky condition and four-hour sub-interval.

Because the OLS utilized specular surfaces to minimize light diffusion and a fixed geometry to redirect light to specific zones in the room, solar position had a strong effect on performance and illustrates the challenges for static light redirecting systems in achieving a consistent improvement in daylight autonomy over conventional systems. The results of the ceiling luminance analysis indicate that the OLS is capable of delivering significantly more light to the ceiling compared to the reference Venetian blind, and with a more uniform luminance distribution. Between 10:00 and 14:00 ST, the OLS produced significantly greater ceiling luminances on average (103\% increase) under clear sky conditions and created a more even ceiling luminance distribution, where the greatest ratio between zones on average was 1.65 , approximately half that of the Venetian blind (2.96). For the other two sub-intervals (6:00-10:00, 14:00-18:00) the performance of the OLS was also better in general in regard to increasing ceiling luminance (Fig. 17) but slightly worse in regard to ceiling luminance uniformity (Fig. 16). Although the OLS did not perform as well in terms of hours of daylight autonomy as the Venetian blind (which was configured with a slat angle set in a horizontal "best-case" condition for daylight transmission), results of the visual discomfort analysis 
show that the OLS produced significantly lower window luminance levels compared to the Venetian blind and never exceeded the designated visual discomfort threshold $\left(2000 \mathrm{~cd} / \mathrm{m}^{2}\right)$.

The OLS was designed to extend the depth of daylight penetration and this particular shallow office test set-up did not allow one to optimally evaluate this aspect of the system. One could speculate that the OLS performance without the intervening walls would have been more favorable at greater depths from the window. This aspect was studied in a companion simulation study [32].

\section{Conclusions}

This study demonstrates that optical sunlight redirecting systems located in the upper "clerestory" zone of the building facade can provide horizontal daylight illuminance levels comparable to a horizontal Venetian blind without the associated window glare, and can deliver a more uniform light distribution across the ceiling plane. Based on side-by-side comparisons of an optical louver system (OLS) and a conventional, matte-white Venetian blind with a horizontal slat angle located inboard of a clerestory window (WWR $=0.174, \mathrm{Tv}=0.62$ ), daylight delivered by the OLS to the workplane at the rear of the room was found to be sufficient to achieve a minimum illuminance of $300 \mathrm{~lx}$ over $100 \%$ of the floor area for $69 \%$ of a $12-\mathrm{h}$ day (October 10) to $16 \%$ of a 12-h day (June 20) under clear sky conditions in a south-facing, $4.6 \mathrm{~m}$ deep, private office mockup. With a $100 \mathrm{~lx}$ threshold, daylight autonomy ranged between $77 \%$ (September 20) and $40 \%$ (July 15) of a 12-h day. Although the OLS produced fewer hours of daylight autonomy than the Venetian blind for approximately two-thirds of the seasonal variation in clear sky conditions, the OLS never exceeded the designated threshold for visual discomfort (average luminance across window $>2000$ $\mathrm{cd} / \mathrm{m}^{2}$ ). In contrast, the Venetian blind was found to exceed the visual discomfort threshold over a large fraction of the day during fall equinox conditions (from 40 to $64 \%$ of the test day between August 22 and October 12). Notably, these peak periods of visual discomfort occurred during the best periods of daylighting performance (based on the $\mathrm{DA}_{300}$ criterion). Further, the OLS was found to direct significantly more sunlight to the ceiling during the middle of the day (10:00-14:00 ST) compared to the Venetian blind (by $103 \%$ for clear skies; approximately $61 \%$ for non-clear skies) and to produce a more uniform luminance distribution across the ceiling. Because conventional Venetian blind slats are often found to be in a far more closed position in real buildings to control window glare than the horizontal (i.e., "open") slat angle used in this study, in practical applications, static optical sunlight redirecting systems have the potential to significantly reduce the annual electrical lighting energy use of a daylit space and improve the quality from the perspective of building occupants by consistently transmitting daylight while eliminating window glare.

\section{Acknowledgements}

The authors would like to acknowledge their LBNL colleagues, Dennis DiBartolomeo and Chad Howdy Goudey, for running the experimental test and to Robert Clear, for his insights into the analysis methods. This work was supported by the Assistant Secretary for Energy Efficiency and Renewable Energy, Office of Building Technology, State and Community Programs, Office of Building Research and Standards of the U.S. Department of Energy under Contract No. DE-AC02-05CH11231.

\section{References}

[1] D\&R International, Ltd. 2012. Buildings Energy Data Book. Table 1.1.5 and Table

3.1.5. Prepared by: D\&R International, Ltd. under contract to Pacific Northwest National Laboratory 2012 for the US Department of Energy, Office of Energy Efficiency and Renewable Energy, Building Technologies Program. Washington, DC.

[2] Shehabi A, DeForest N, McNeil A, Masanet E, Lee ES, Milliron D. 2013. US energy savings potential from dynamic daylighting control glazings. Energy and Buildings 66 (2013): 415-423.

[3] Grondzik W, Kwok A, Reynolds J, Stein. 2009. Mechanical and Electrical Equipment for Buildings 
$11^{\text {th }}$ edition. John Wiley and Sons Inc., Hoboken, New Jersey.

[4] Bordass B., Heasman, T., Leaman, A., Perry, M. 1994. Daylight use in open plan offices: The opportunities and the fantasies. CIBSE Lighting Conference, Cambridge, March 1994.

[5] International Energy Agency. 2000. Daylight in Buildings: a Source Book on Daylighting Systems and Components. Report of IEA SHC Task 21 / ECBCS Annex 29, July 2000.

http://gaia.lbl.gov/iea21/

[6] Littlefair, Paul J. "Light shelves: computer assessment of daylighting performance." Lighting Research and Technology 27.2 (1995): 79-91.

[7] Beltran, L. O., et al. "The design and evaluation of three advanced daylighting systems: light shelves, light pipes and skylights." Proceedings of the Solar'94 Conference, Golden Opportunities for Solar Prosperity, American Solar Energy Society, Inc. 1994.

[8] Scartezzini, Jean-Louis, and Gilles Courret. "Anidolic daylighting systems." Solar Energy 73.2 (2002): 123-135.

[9] Reinhart, Christoph F., and Marilyne Andersen. "Development and validation of a Radiance model for a translucent panel." Energy and Buildings 38.7 (2006): 890-904.

[10] Wadsworth F. Illuminating prism structure, US Patent 720,386, February 10, 1903.

[11] Thanachareonkit, Anothai, Eleanor S. Lee, and Andrew McNeil. "Empirical assessment of a prismatic daylight-redirecting window film in a full-scale office testbed." LEUKOS 10.1 (2014): 19-45.

[12] Bartenbach C, Möeller M, Lanzenberger R. Arrangement for illuminating a room with daylight, US Patent 4,699,467, October 13, 1987.

[13] Light Louver Daylighting System. Product description webpage. Accessed 3/31/2015. http://lightlouver.com/lightlouverdescription/

[14] Konis, K., E.S. Lee, R.D. Clear, Ph.D. 2011. Visual Comfort Analysis of Innovative Interior and Exterior Shading Systems for Commercial Buildings Using High Resolution Luminance Images. Journal of the Illuminating Engineering Society of North America (LEUKOS). Volume 7, No. 3, pp. 167-188.

[15] U.S. Green Building Council (U.S.G.B.C.). 2014. Leadership in Energy and Environmental Design (LEED) rating system for Building Design and Construction $(\mathrm{BD}+\mathrm{C})$ version 4.

[16] Building Research Establishment. 2014. Building Research Establishment Environmental Assessment Methodology (BREEAM).

[17] Ward, Gregory, et al. "Simulating the daylight performance of complex fenestration systems using bidirectional scattering distribution functions within Radiance." Leukos 7.4 (2011): 241-261.

[18] McNeil, Andrew, and E. S. Lee. "A validation of the Radiance three-phase simulation method for modelling annual daylight performance of optically complex fenestration systems." Journal of Building Performance Simulation 6.1 (2013): 24-37.

[19] Ward, Greg. HDRGEN high dynamic range image builder (software program). Anyhere software. Accessed 3/31/2015. http://www.anyhere.com/

[20] Mitsunaga T. and S.K. Nayar. 1999. "Radiometric Self Calibration," IEEE Conference on Computer Vision and Pattern Recognition (CVPR), Vol.1, pp.374-380, Jun, 1999. 
[21] Inanici M, and Galvin J. 2004. "Evaluation of high dynamic range photography as a luminance mapping technique." Lawrence Berkeley National Laboratory.

[22] Darula S. and R. Kittler. 2004. Sunshine Duration and Daily Courses of Illuminance in Bratislava. International Journal of Climatology 24: 1777-1783.

[23] Reinhart, C.F. 2004. Lightswitch-2002: A model for manual and automated control of electric lighting and blinds. Solar Energy 77 (1):15-28.

[24] Illuminating Engineering Society of North America. 2011. The Lighting Handbook, Tenth Edition. Illuminating Engineering Society of North America, 120 Wall Street, New York, New York 10005.

[25] Nabil, Azza, and John Mardaljevic. "Useful daylight illuminance: a new paradigm for assessing daylight in buildings." Lighting Research and Technology 37.1 (2005): 41-57.

[26] National Research Council Canada (NRC), Institute for Research Construction (IRC), The Cost-Effective Open-Plan Environment (COPE), The COPE Project: Building a Better Workstation. Available from URL: http://irc.nrc-cnrc.gc.ca/ie/cope/cope-en.pdf

[27] Schuler M. Building simulation in application: developing concepts for low energy buildings through a co-operation between architect andengineer: Proceedings of the Solar World Congress, the International Solar Energy Society (ISES). Harare: Zimbabwe, September, 1995.

[28] Konis K. "Effective daylighting: evaluating daylighting performance in the San Francisco federal building from the perspective of building occupants." (2011).

[29] Einhom, H. D. "Unified glare rating (UGR): Merits and application to multiple sources." Lighting Research and Technology 30.2 (1998): 89-93.

[30] Wienold, Jan, and Jens Christoffersen. "Evaluation methods and development of a new glare prediction model for daylight environments with the use of CCD cameras." Energy and buildings 38.7 (2006): 743-757.

[31]Larson, Greg Ward, et al. Rendering with Radiance: the art and science of lighting visualization. San Francisco, CA: Morgan Kaufmann, 1998.

[32] McNeil, A., and E. S. Lee. Annual Assessment of an Optically-Complex Daylighting System Using Bidirectional Scattering Distribution Functions with Radiance, DOE. LBNL FY10 Technical Report Deliverable, 2010. 


\begin{tabular}{|c|c|c|c|c|c|c|c|}
\hline \multirow{2}{*}{$\begin{array}{l}\text { Clear Skies } \\
\text { Date }(\mathrm{N}=21)\end{array}$} & \multirow[b]{2}{*}{ 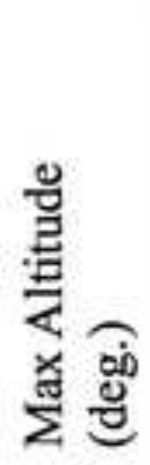 } & \multicolumn{3}{|c|}{ Test Condition (OLS) } & \multicolumn{3}{|c|}{ Reference Condition } \\
\hline & & 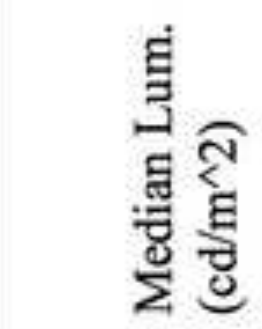 & 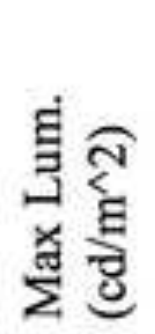 & 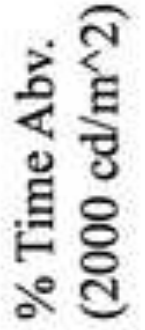 & 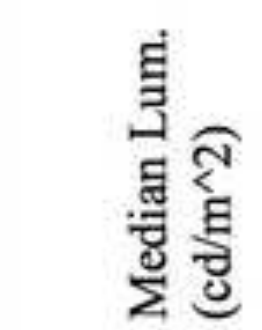 & 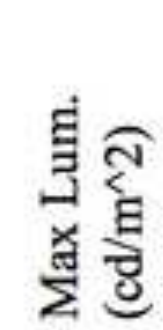 & 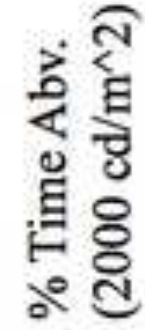 \\
\hline 20100730 & 29.5 & 16 & 57 & $0 \%$ & 669 & 2314 & $3 \%$ \\
\hline 20100716 & 29.5 & 67 & 215 & $0 \%$ & 618 & 1839 & $0 \%$ \\
\hline 20100715 & 29.6 & 51 & 193 & $0 \%$ & 528 & 1751 & $0 \%$ \\
\hline 20100714 & 29.6 & 56 & 187 & $0 \%$ & 543 & 1723 & $0 \%$ \\
\hline 20100713 & 32.3 & 73 & 321 & $0 \%$ & 579 & 2159 & $1 \%$ \\
\hline 20100620 & 32.7 & 66 & 191 & $0 \%$ & 548 & 1497 & $0 \%$ \\
\hline 20100801 & 37.8 & 18 & 49 & $0 \%$ & 731 & 2031 & $1 \%$ \\
\hline 20100802 & 44.4 & 16 & 54 & $0 \%$ & 680 & 2167 & $10 \%$ \\
\hline 20100822 & 44.8 & 42 & 84 & $0 \%$ & 1363 & 3810 & $40 \%$ \\
\hline 20100823 & 45.18 & 42 & 85 & $0 \%$ & 1388 & 3864 & $41 \%$ \\
\hline 20100824 & 62.94 & 44 & 86 & $0 \%$ & 1428 & 3943 & $41 \%$ \\
\hline 20101010 & 63.28 & 145 & 1854 & $0 \%$ & 3724 & 13546 & $64 \%$ \\
\hline 20101011 & 63.62 & 133 & 1617 & $0 \%$ & 3538 & 13155 & $63 \%$ \\
\hline 20101012 & 70.56 & 137 & 1083 & $0 \%$ & 3697 & 10152 & $64 \%$ \\
\hline 20101031 & 70.81 & 160 & 525 & $0 \%$ & 1294 & 2124 & $0 \%$ \\
\hline 20110119 & 71.31 & 129 & 308 & $0 \%$ & 1201 & 1870 & $0 \%$ \\
\hline 20110117 & 73.36 & 129 & 190 & $0 \%$ & 1235 & 1948 & $0 \%$ \\
\hline 20101227 & 73.53 & 63 & 185 & $0 \%$ & 336 & 1575 & $0 \%$ \\
\hline 20101226 & 73.69 & 49 & 180 & $0 \%$ & 136 & 1584 & $0 \%$ \\
\hline 20101224 & 73.84 & 70 & 151 & $0 \%$ & 460 & 1297 & $0 \%$ \\
\hline 20101223 & 75.59 & 110 & 175 & $0 \%$ & 817 & 1607 & $0 \%$ \\
\hline
\end{tabular}



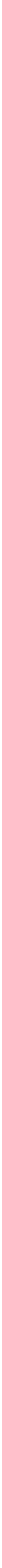


\section{Average Illuminance at Rear Workplane Sensors}
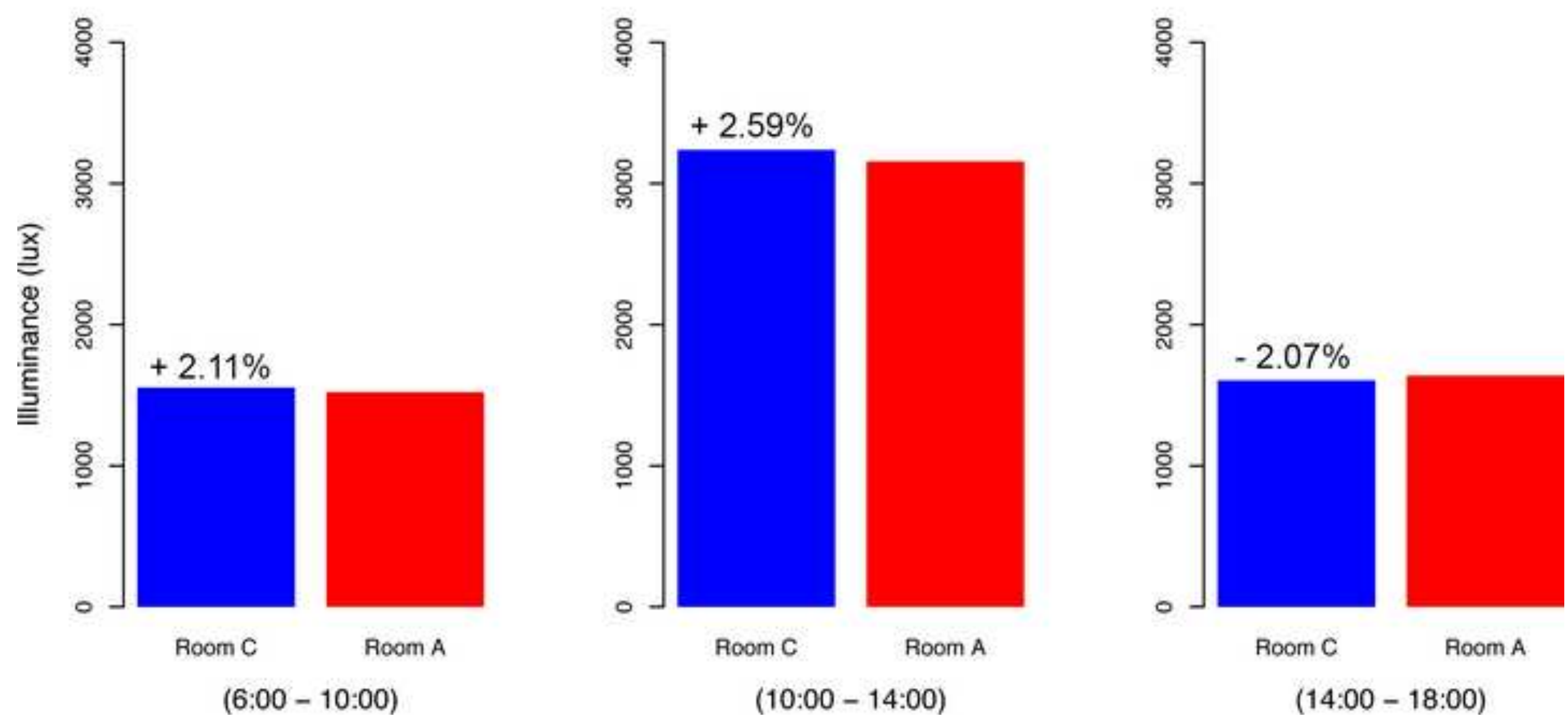


\section{Sky Condition Summary}

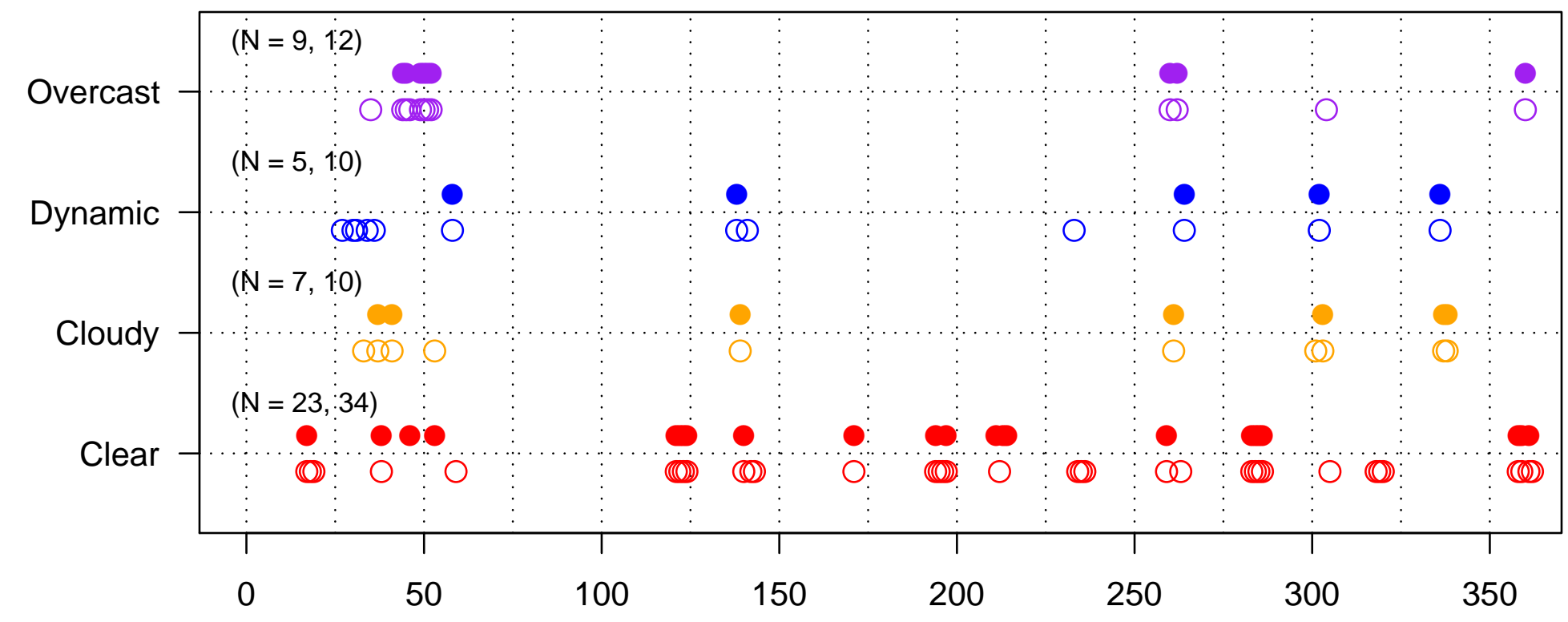

Day Number 


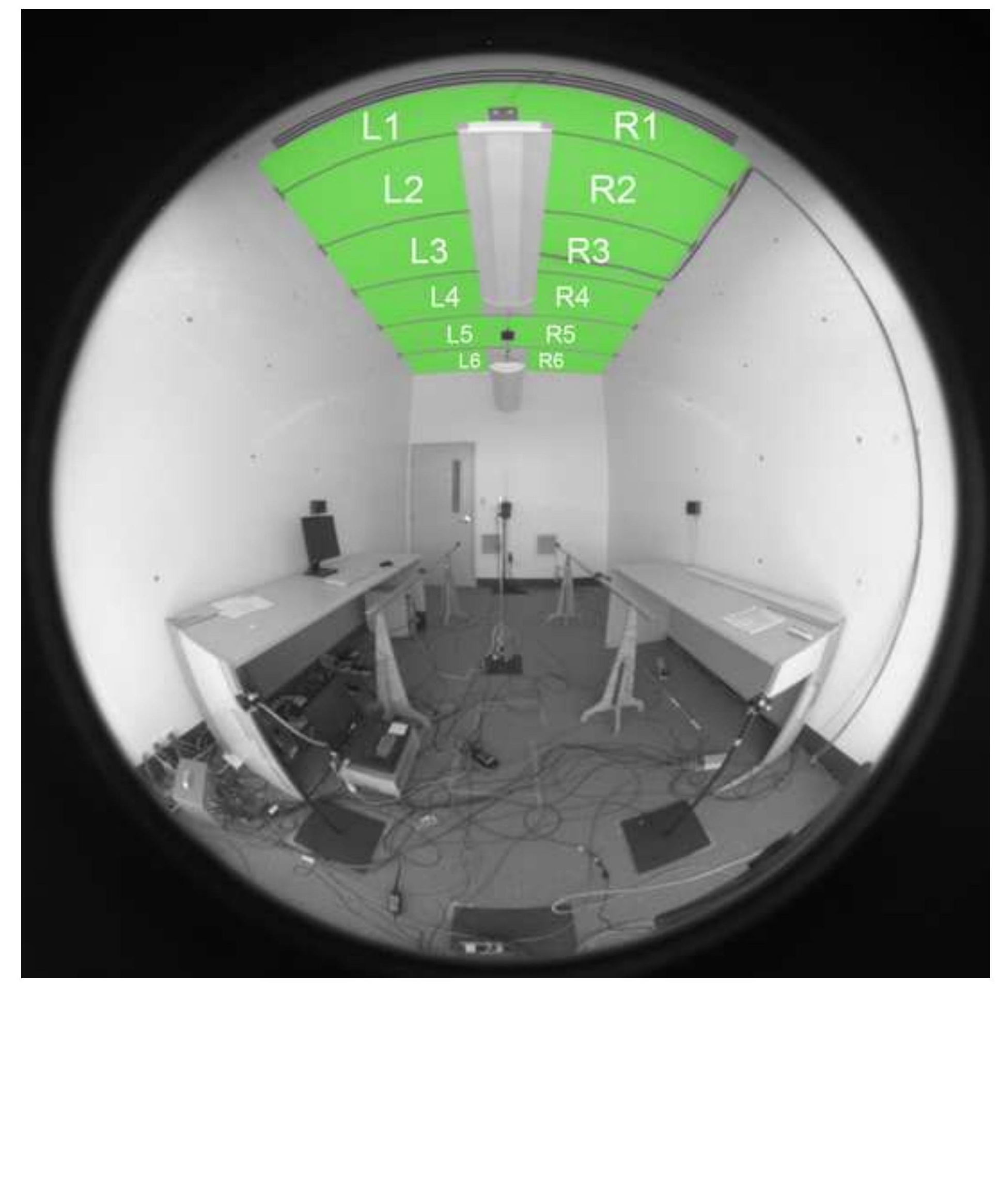

Figure
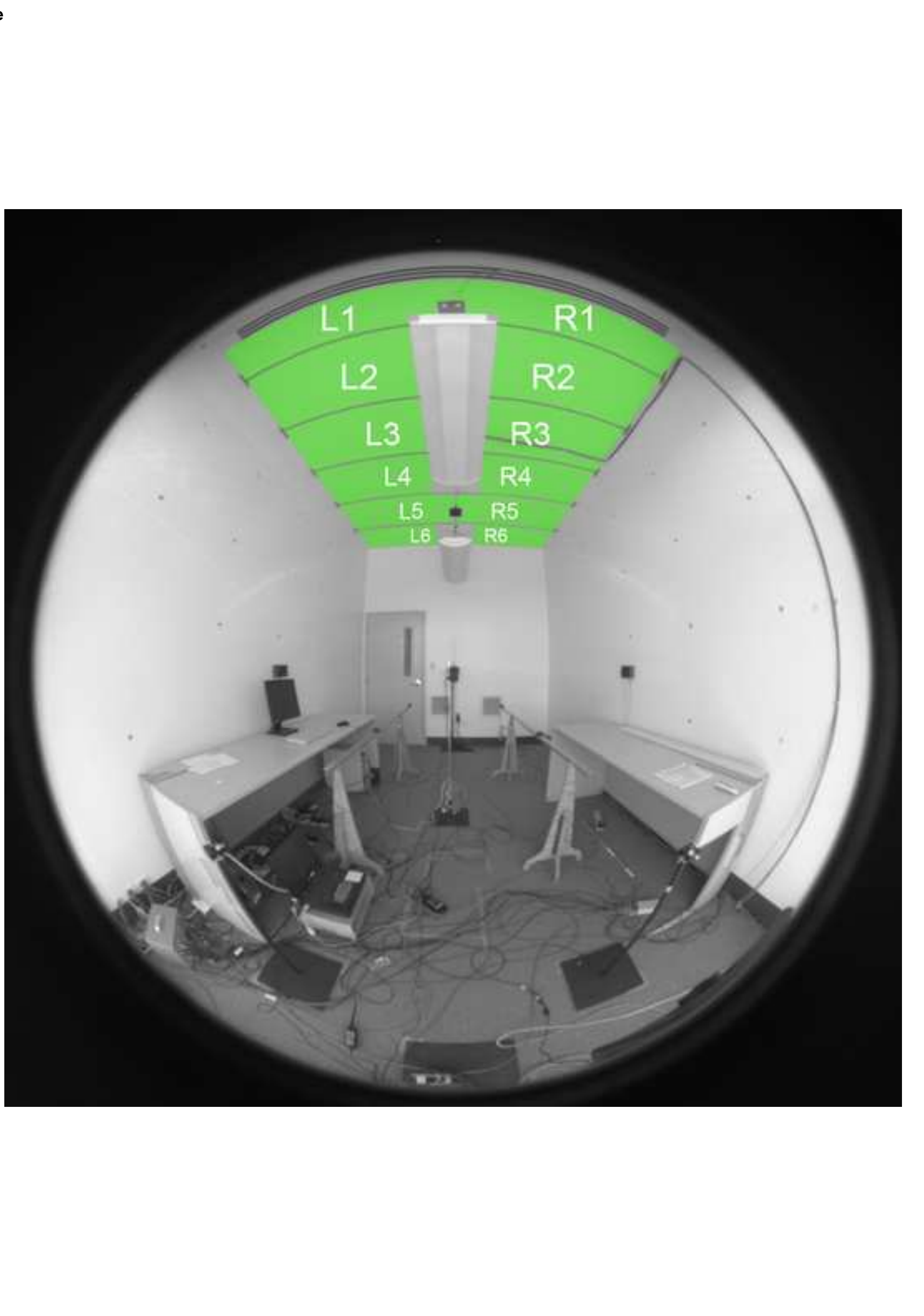

(⿸丆口




\section{Seasonal Variation in Daylight Autonomy (Clear Skies)}

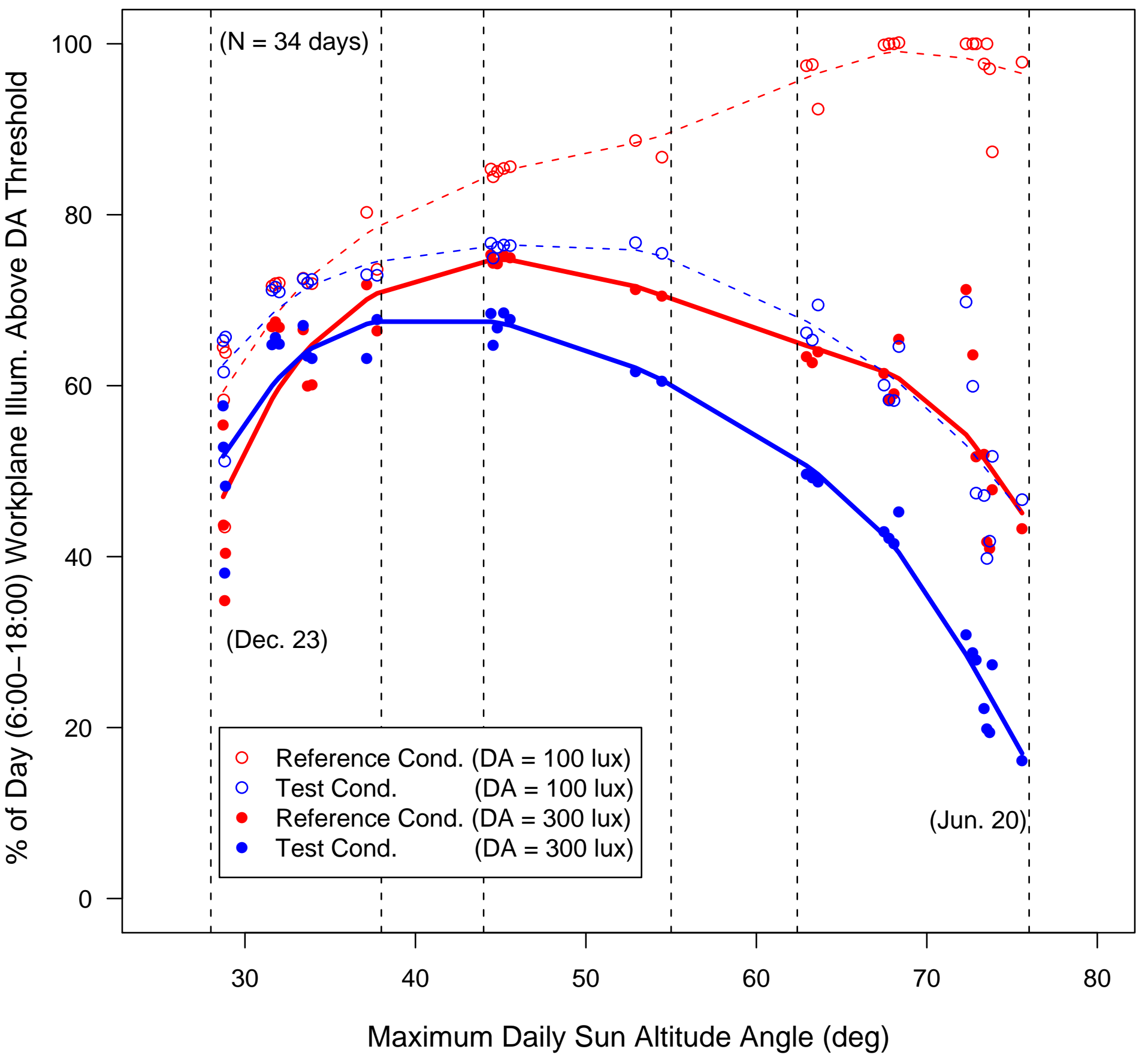


Seasonal Variation in Daylight Autonomy (Dynamic Skies)

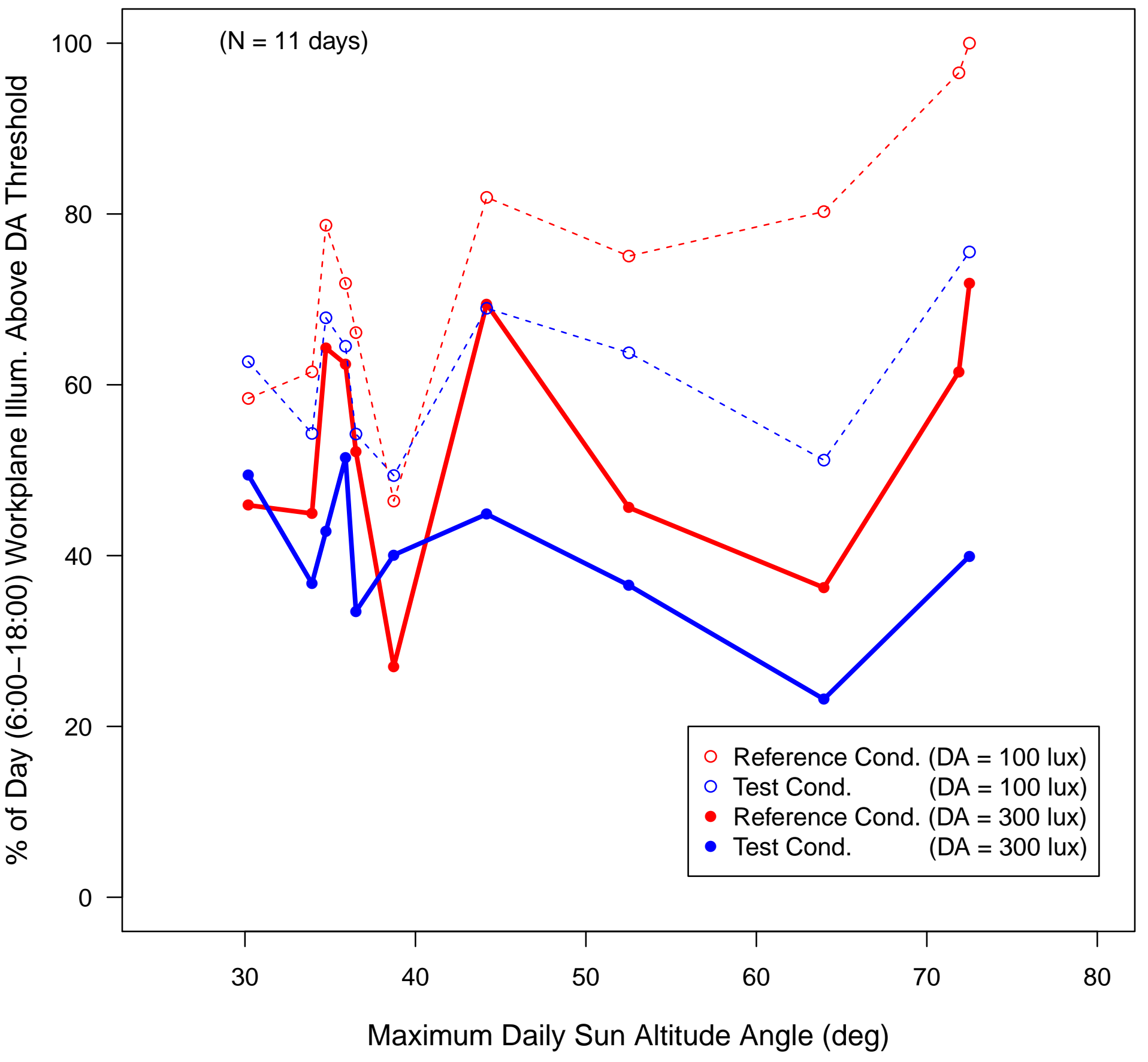




\section{Seasonal Variation in Daylight Autonomy (Overcast Skies)}

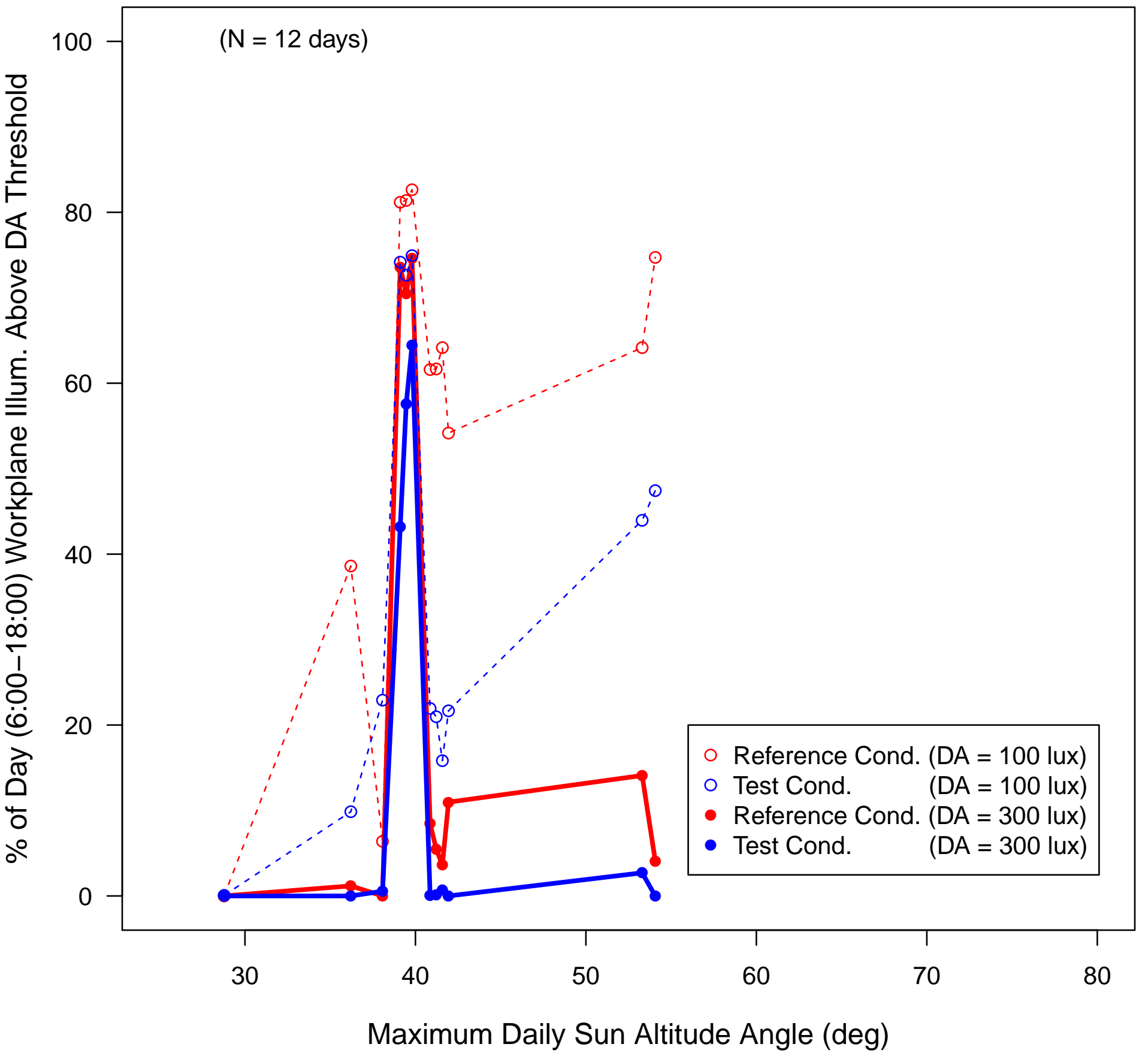




\section{Seasonal Variation in Visual Comfort (Clear Skies)}

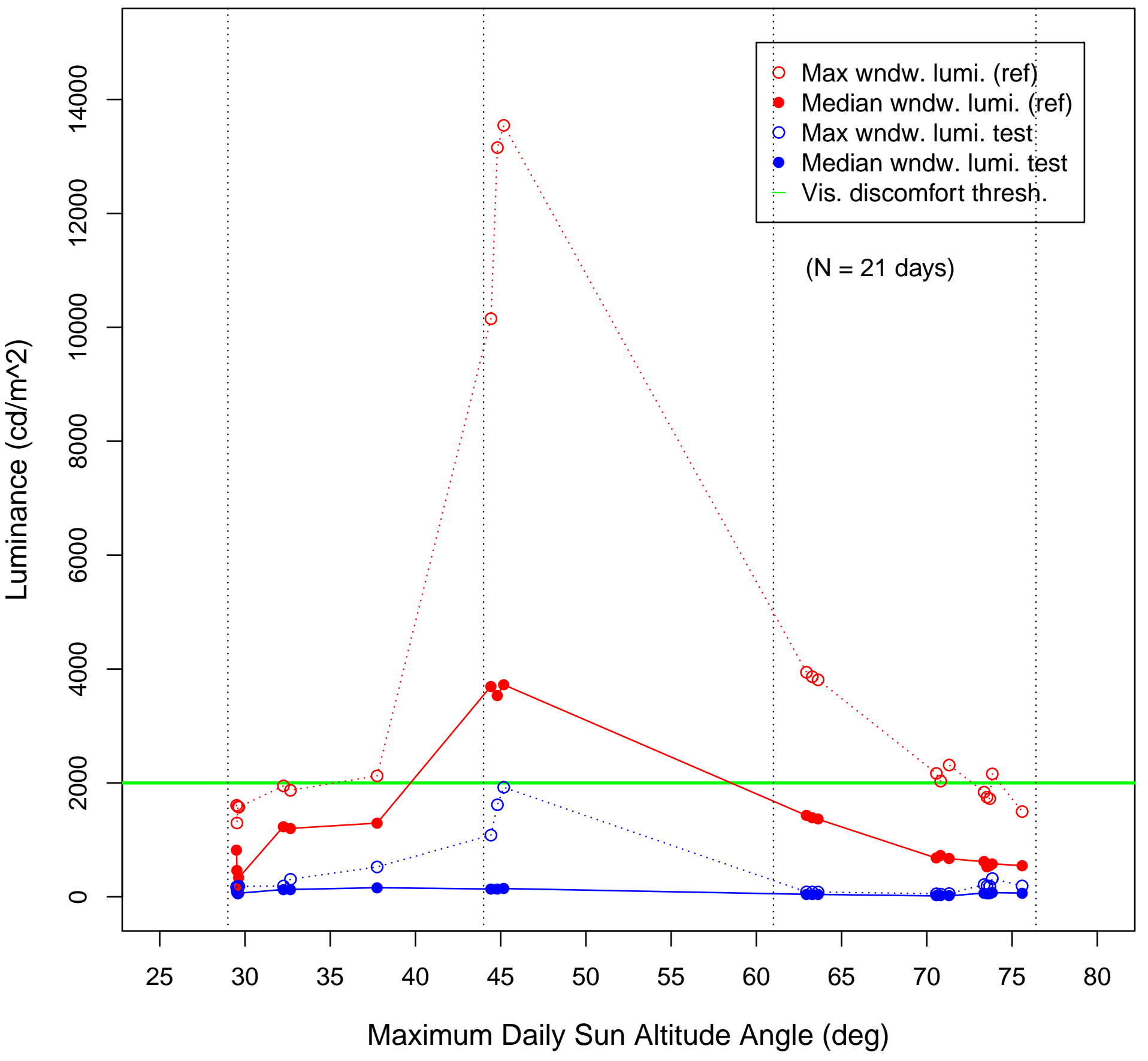




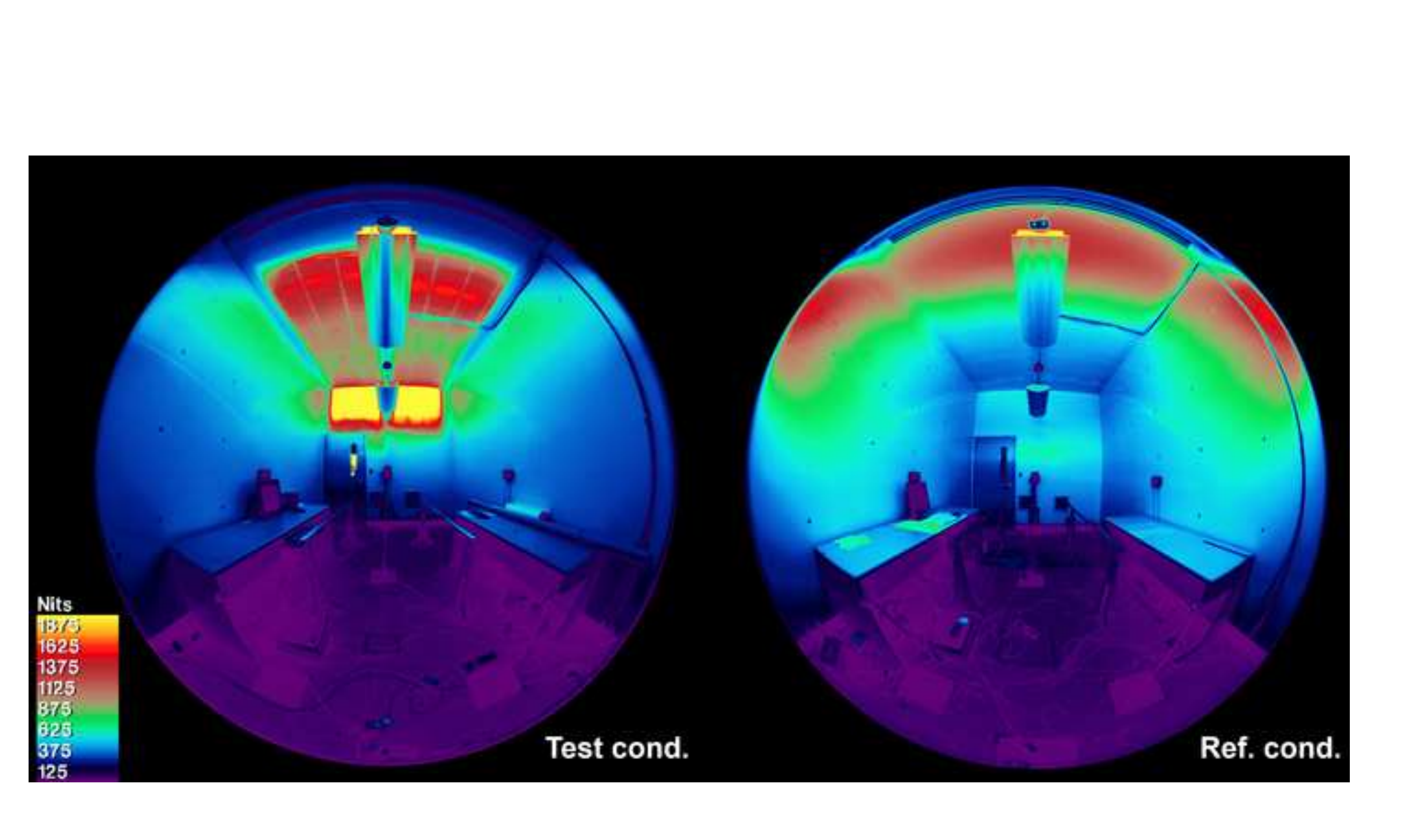

$15 \% 15$

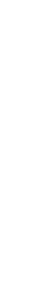

更

-

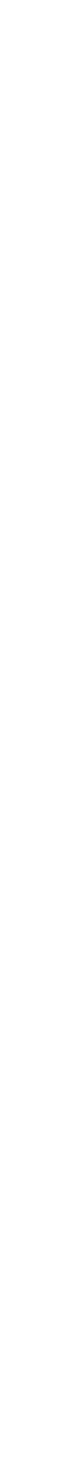



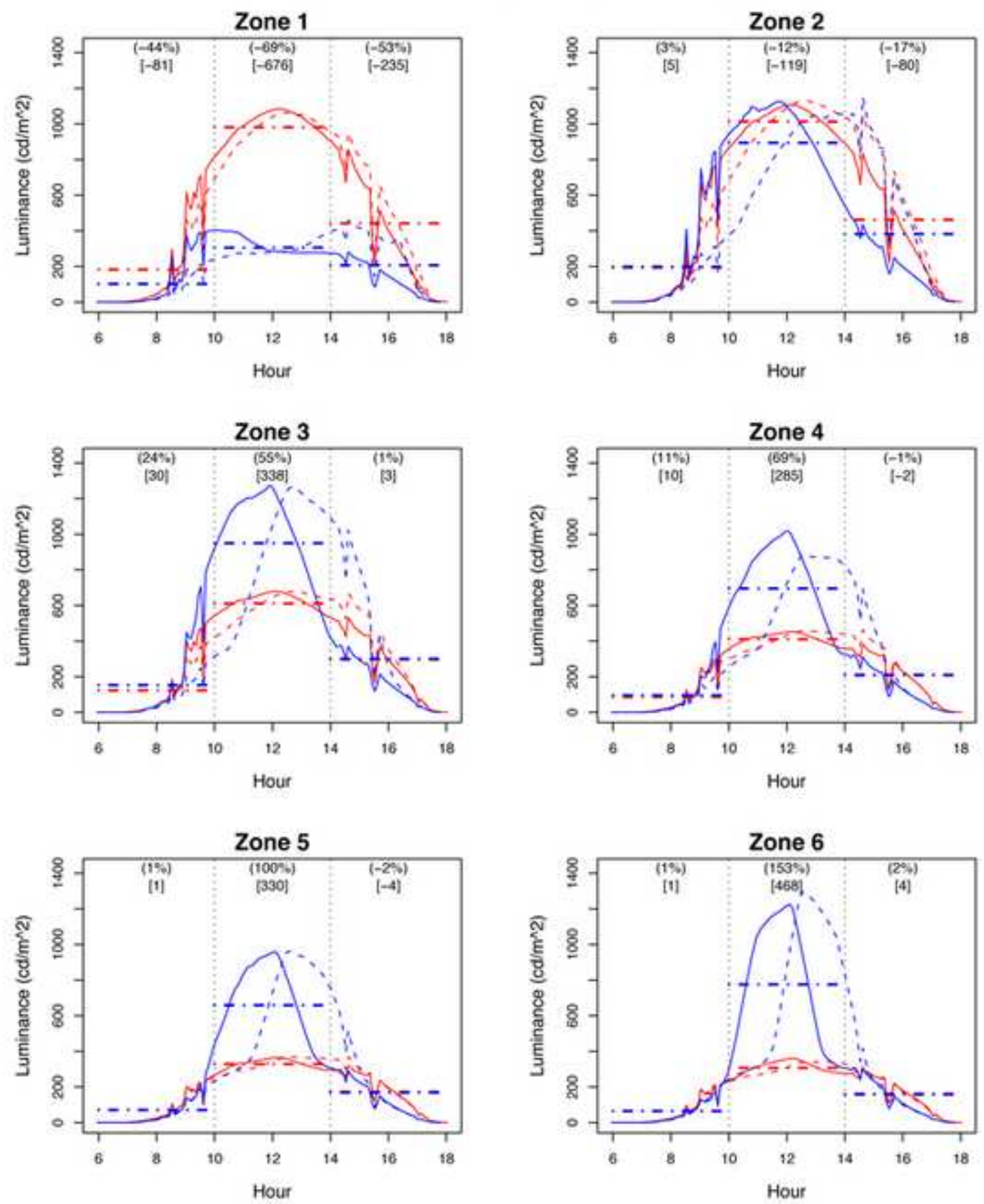
Ceiling Luminance By Zone (Overcast Sky)
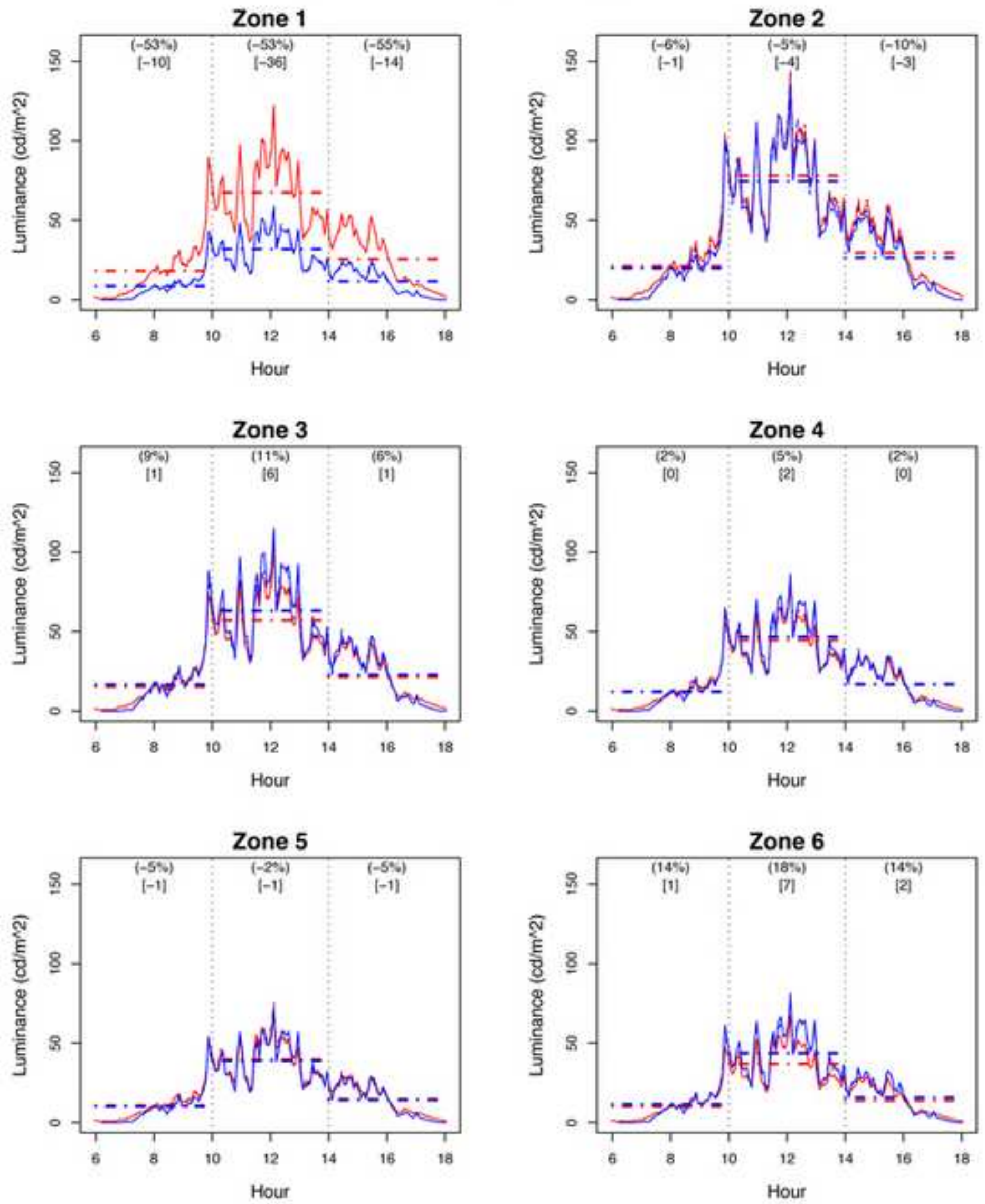

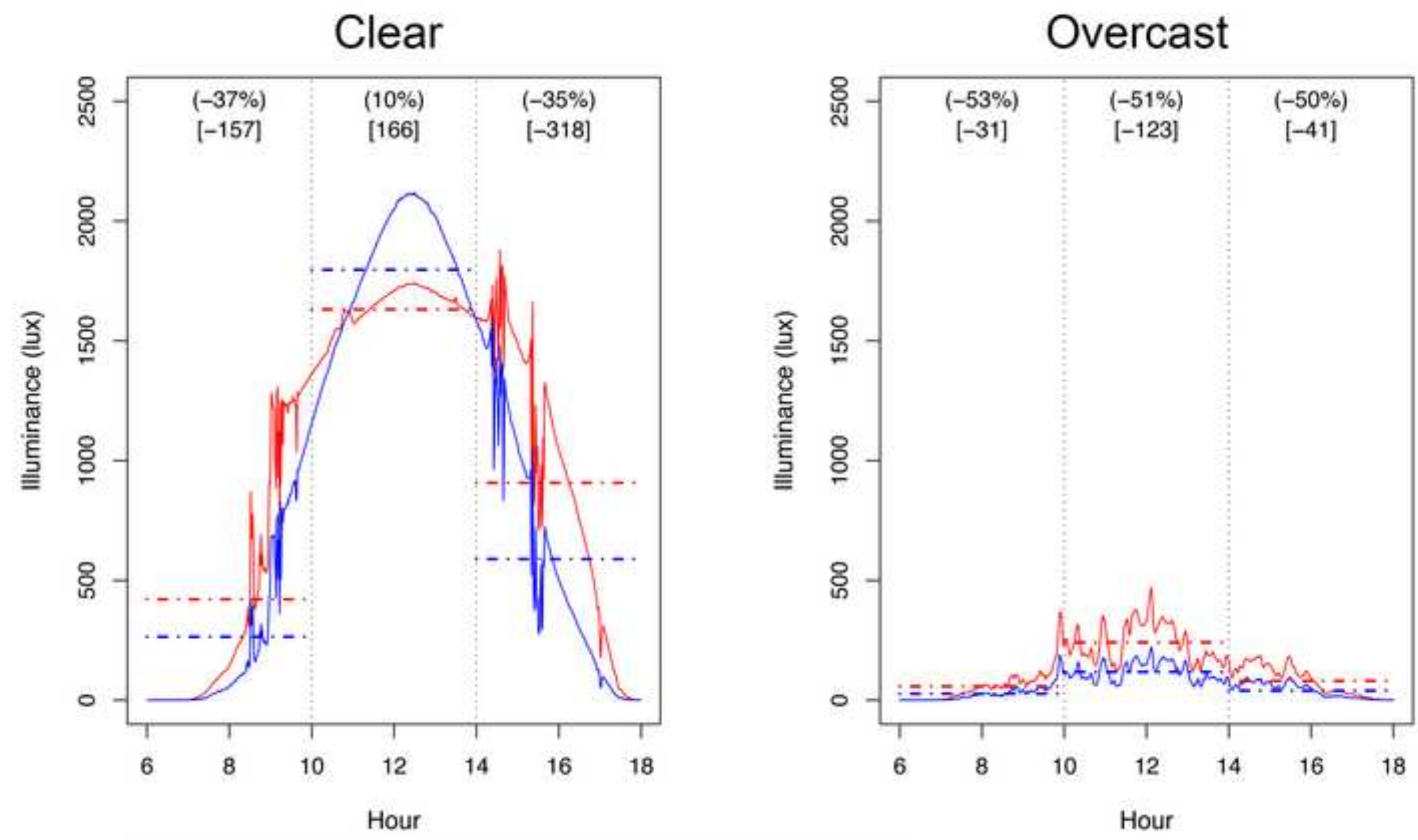

$$
\text { — Test Cond. _— Ref Cond. .-- Test Mean .- Ref Mean }
$$


Test Cond. (6:00-10:00, 14:00-18:00)

$(\mathrm{N}=23$ days $)$

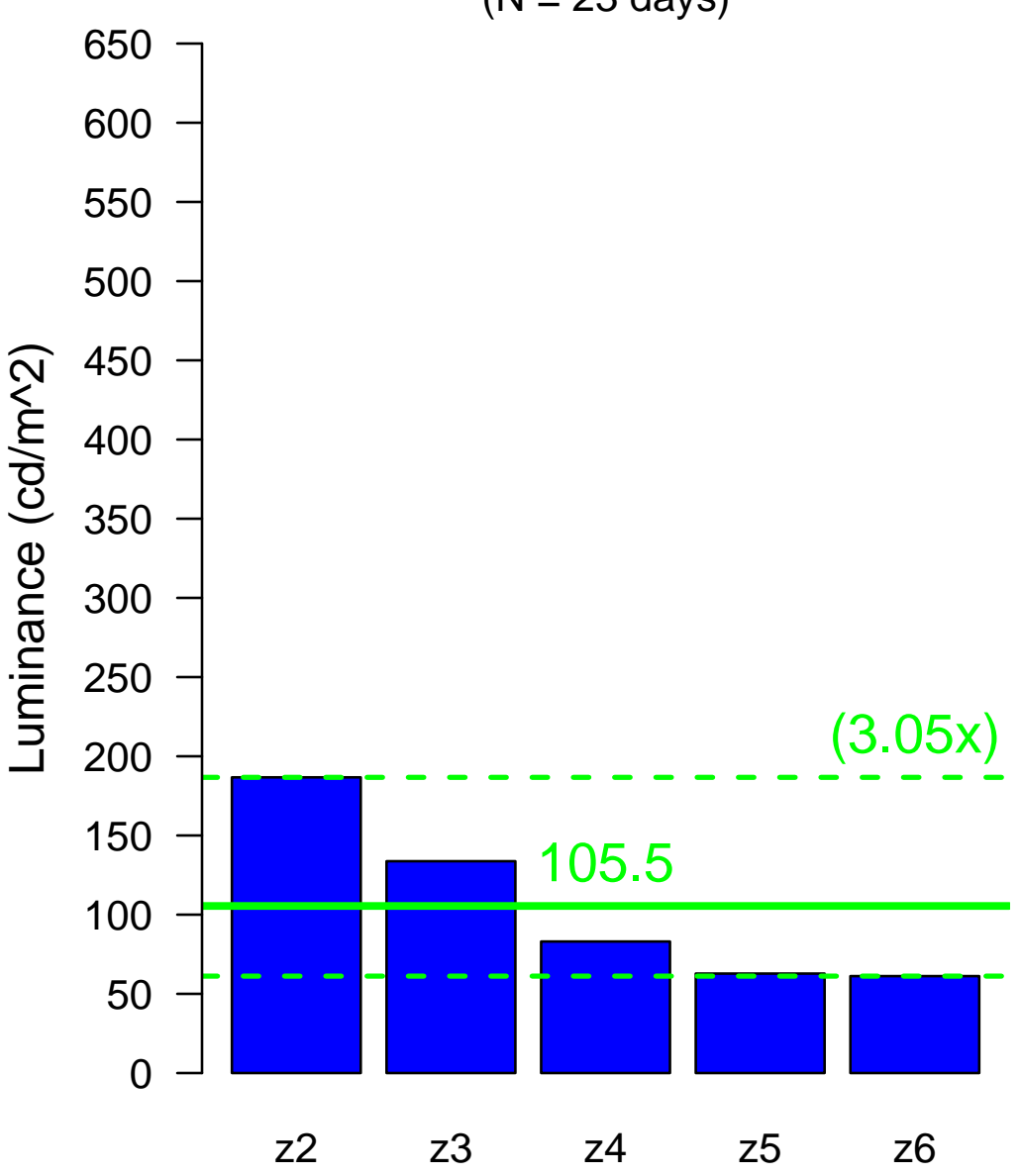

Ceiling Zone
Reference Cond. (6:00-10:00, 14:00-18:00) $(\mathrm{N}=23$ days $)$

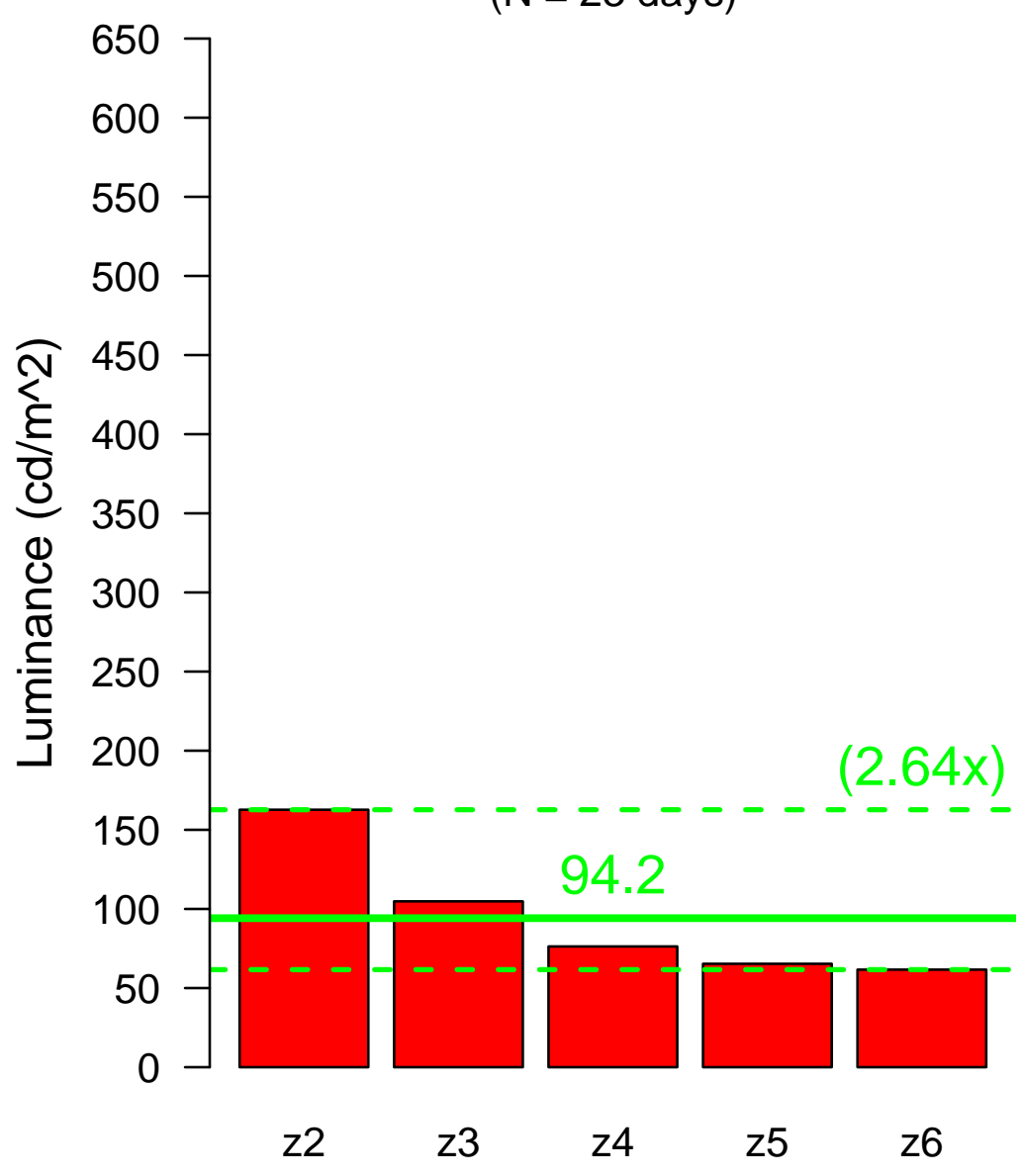

Ceiling Zone 

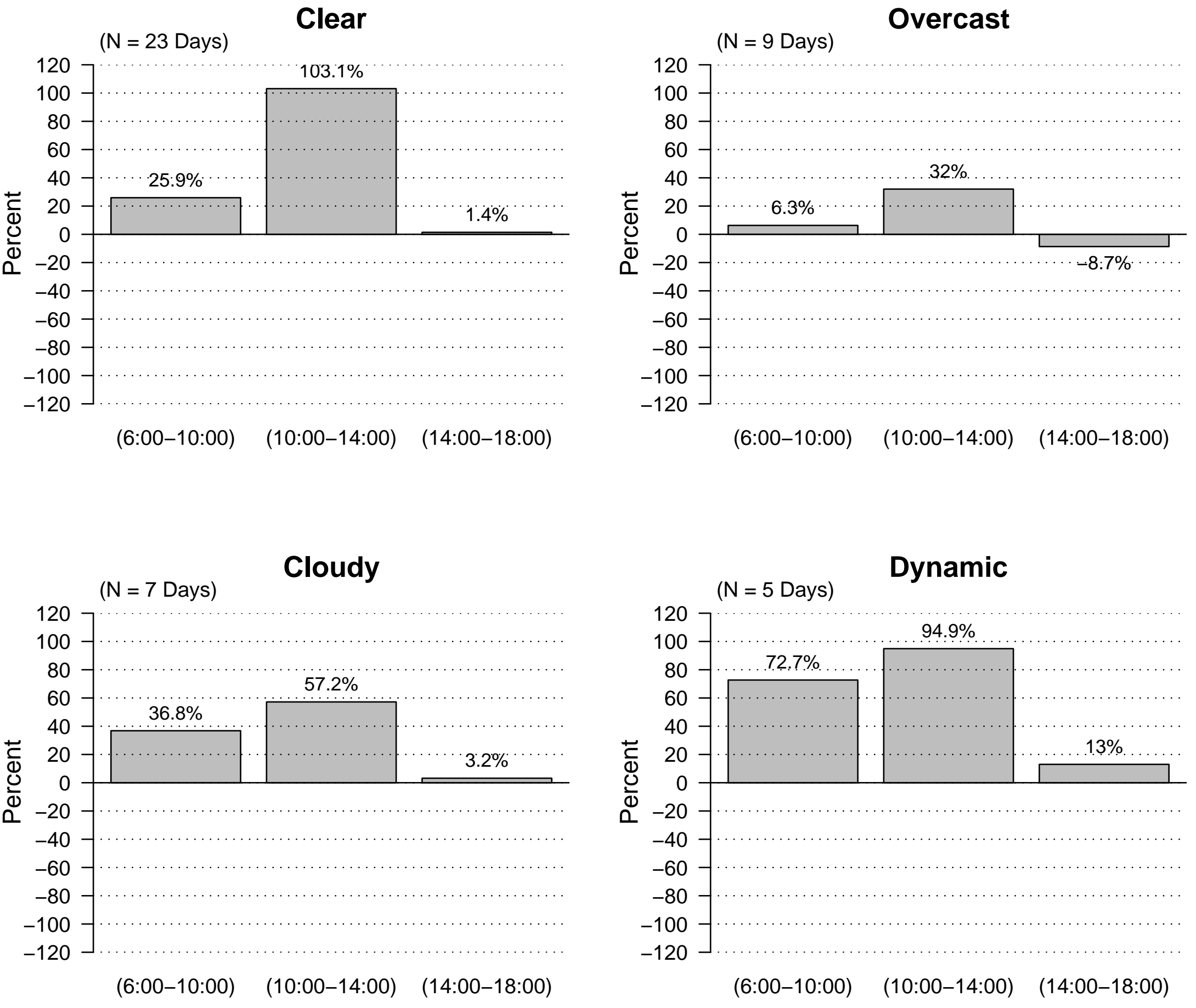